\title{
SPORTS ANTHROPOLOGICAL COMPARISON BETWEEN MALE MARTIAL ARTS FIGHTERS AND THE STUDENTS MAJORING IN PHYSICAL EDUCATION
}

\author{
CHRISTOPH KRICK, CHRISTOPH RASCHKA \\ Institute of Sports Science, Julius-Maximilians-University Würzburg, Germany
}

\begin{abstract}
The goal of the present study is to present the differences in the body composition of male Muay Thai fighters and the students majoring in physical education. The students majoring in physical education served as a control group.

The two groups (Muay Thai fighters and the students majoring in physical education) were divided into four groups: Experienced Muay Thai fighters and less experienced Muay Thai fighters as well as experienced students majoring in physical education and less experienced students majoring in physical education. The definition for "experienced" has been used when someone was engaged in sports longer than 10 hours a week.

All the measurements of this study have been taken under the standardized measurement procedure by the author of this study. The results have been statistically analyzed with the program SPSS.

The study shows that the experienced Muay Thai fighters are significantly smaller (the average body height of $177.2 \mathrm{~cm}$ ) than the experienced students majoring in physical education (the average body height 184.1).

Other data in the study which used the methods developed by Conrad, Knussmann, Parnell and Heath and Carter show that, while the experienced Muay Thai fighters are significantly smaller than the other participants, they are nonetheless better trained (more muscle tissue) than their counterparts.
\end{abstract}

Key words: Sports anthropology, Muay Thai, Martial Arts, Body Composition, Somatotype. 


\section{INTRODUCTION}

Muay Thai is a martial arts discipline that has existed for more than 2000 years. This form of martial arts has its origins in southern China. It was practiced by the Ao Lei tribes. In fact, the Ao Lei tribes brought this type of martial arts to Siam (Thailand).

Until the year 1920 Muay Thai was a part of the school curricula in Thailand. Even though it is not an integral part anymore, Muay Thai remains the nation's traditional and most practiced type of martial arts. During the last decade Muay Thai has become popular among Westerners. In the USA and Europe there is much interest shown in this sport.

Muay Thai is a martial arts sport which requires great physical condition. Muay Thai allows punches and kicks. Therefore one can assume that the trained muscle tissue is of essence in order to be able to win a tournament.

This study is aimed at analyzing whether the body composition of the experienced Muay Thai fighters shows any specifics that could lead to the assessment that their body composition makes them more successful in tournaments.

\section{The participants in the study}

In this study 70 people participated. All the participants were males and at least 16 years of age. The average age of the participants is 24 years.

30 male participants in this study go in for Muay Thai. 40 male participants are the students majoring in physical education. These two groups were divided into two sub-groups; that means into experienced and less experienced sportsmen. The definition of experienced in this study is based on the number of hours a participant actively trained during the week. All the participants who trained less than ten hours a week were defined as less experienced. Those who trained more than ten hours a week were defined as experienced.

All the participants in this study lived in the Rhine-Main area in Germany where the measurements took place.

\section{Anthropometric measurements}

The Body Mass Index of the participants in this study shows that the experienced Muay Thai fighters had the highest values. The result is seen in Table 1. 
Table 1. Body Mass Index (in $\mathrm{kg} / \mathrm{m}^{2}$ )

\begin{tabular}{llllcl}
\hline participants & \multicolumn{1}{c}{ experience } & mean & $\mathbf{n}$ & $\begin{array}{c}\text { Standard } \\
\text { Deviation }\end{array}$ & $\begin{array}{c}\text { Standard } \\
\text { Error }\end{array}$ \\
\hline \multirow{2}{*}{ students } & unexperienced & 24.64 & 15 & 2.25 & 0.58 \\
\cline { 2 - 6 } & experienced & 24.39 & 25 & 2.15 & 0.43 \\
\cline { 2 - 6 } & all & 24.48 & 40 & 2.16 & 0.34 \\
\hline $\begin{array}{l}\text { Muay Thai } \\
\text { fighters }\end{array}$ & unexperienced & 24.04 & 15 & 2.10 & 0.54 \\
\cline { 2 - 6 } & experienced & 26.34 & 15 & 2.81 & 0.72 \\
\cline { 2 - 6 } & all & 25.19 & 30 & 2.70 & 0.49 \\
\hline all & unexperienced & 24.34 & 30 & 2.16 & 0.39 \\
\cline { 2 - 6 } & experienced & 25.12 & 40 & 2.57 & 0.40 \\
\cline { 2 - 6 } & all & 24.79 & 70 & 2.42 & 0.28 \\
\hline
\end{tabular}

Other results concerning the somatotype of the different participants are based on the methods created by Conrad, Knussmann, Parnell and Heath and Carter.

\section{Parnell}

The results of the somatochart based on the method of Parnell show that the experienced as well as the less experienced Muay Thai fighters are found mainly around the 4-4-4. However, the experienced Muay Thai fighters tend to have a more meso-ectomorphic body composition than the less experienced ones. (Figure 2)

The somatotypes of the students majoring in physical education (Figure 1) tend to be found more in the endomorph- ectomorph region.

\section{Conrad}

The majority of the experienced Muay Thai fighters show a trend to pycnomorphy in Figure 6 whereas the rest of the participants (students and less experienced Muay Thai fighters (shown in Figures 3-5) show a balance between pycnomorphy and leptomorphy. All the participants are dominant in the hyperplastic region.

\section{Tittel and wutscherk}

The AKS- Index was used in the present study in order to determine the lean body substance of the different athletes. The results shown in Table 2 show that the Muay Thai fighters had a slightly higher AKS- Index than the students. 


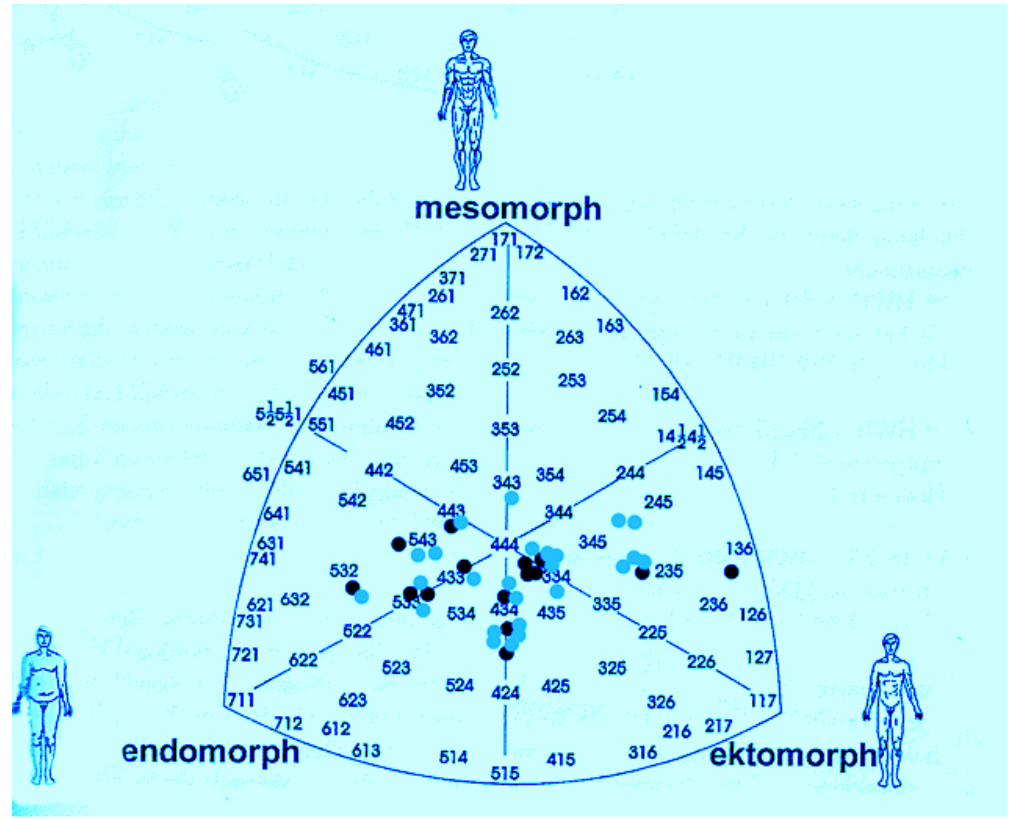

Figure 1. Somatochart according to the Parnell's method. The black dots represent the inexperienced students, the grey dots represent the experienced ones.

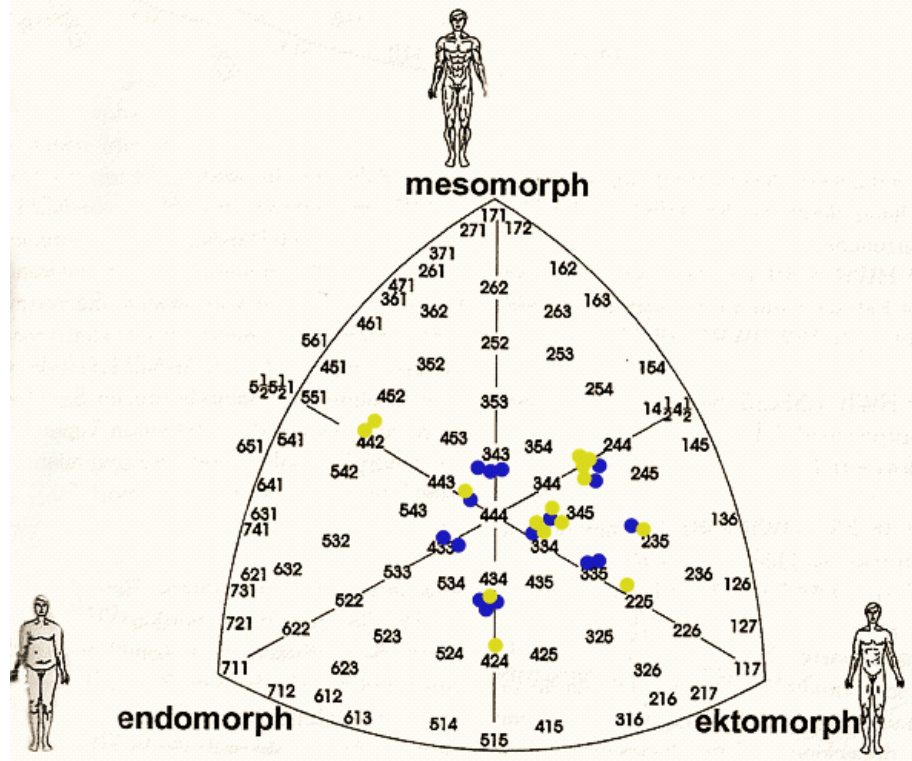

Figure 2. Somatochart according to the Parnell's method. The black dots represent the inexperienced Muay Thai fighters, the grey dots represent the experienced ones. 


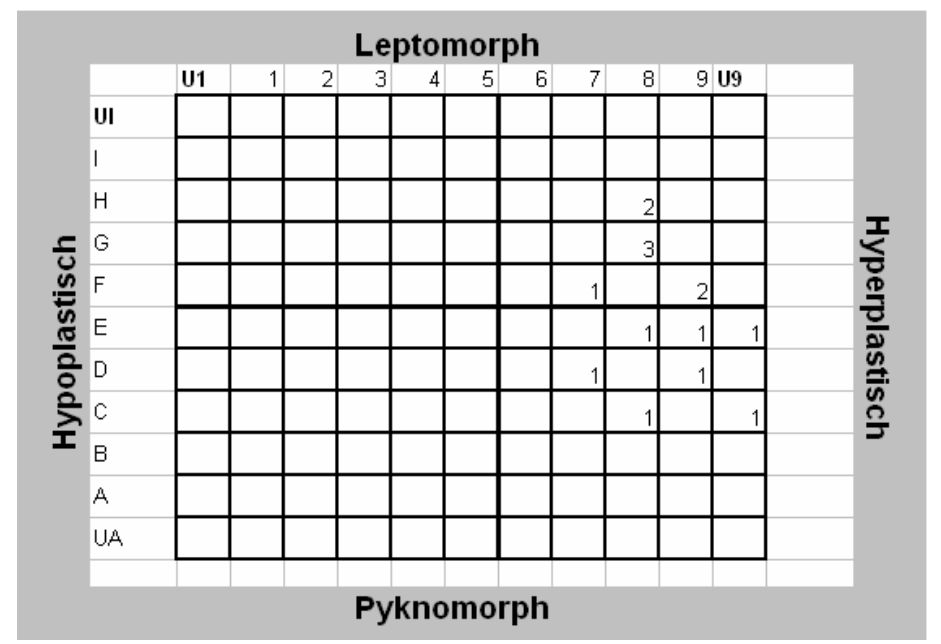

Figure 3. Conrad's chessboard sample: Inexperienced students

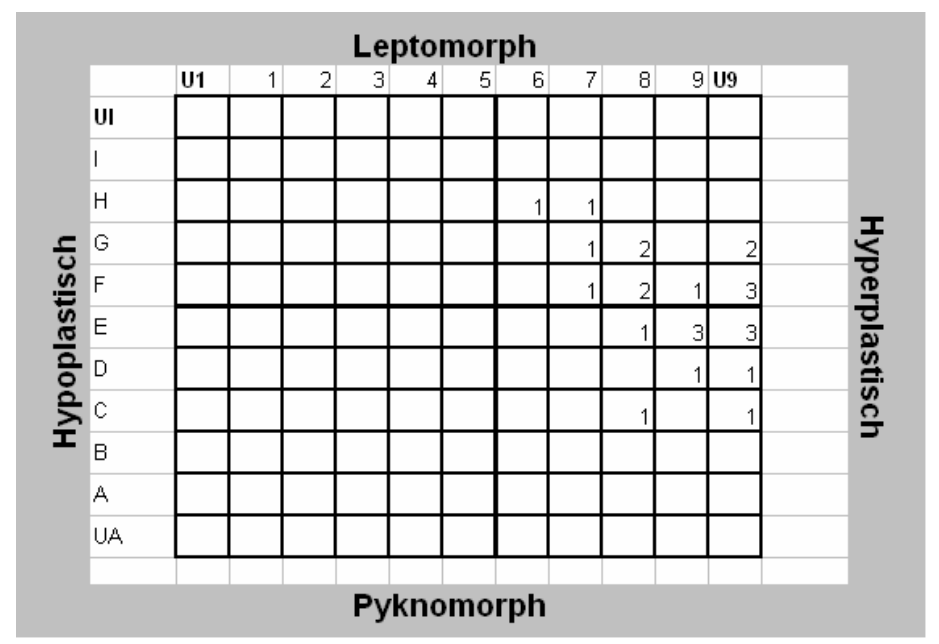

Figure 4. Conrad's chessboard sample: Experienced students 


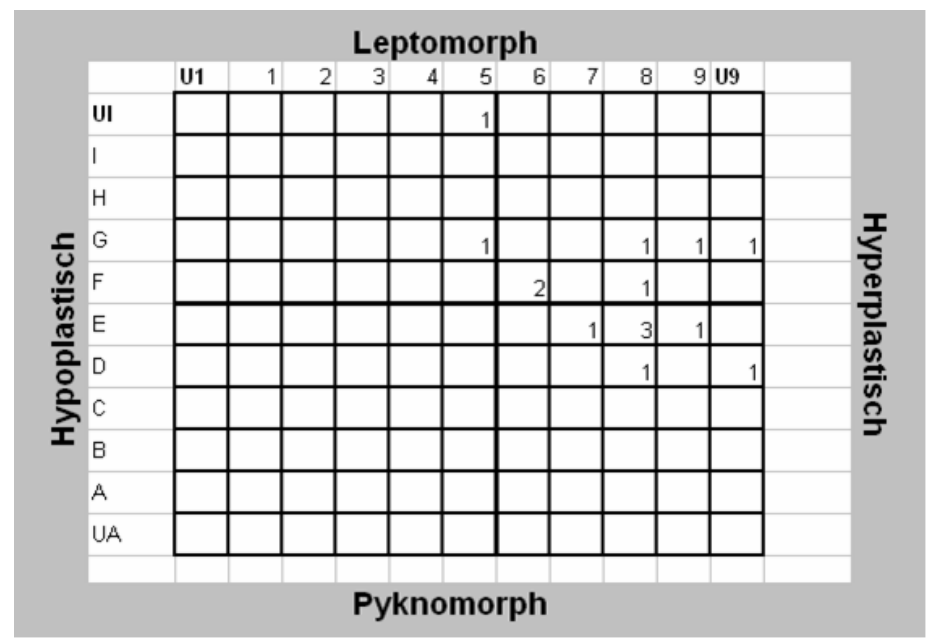

Figure 5. Conrad's chessboard sample: Inexperienced Muay Thai fighters

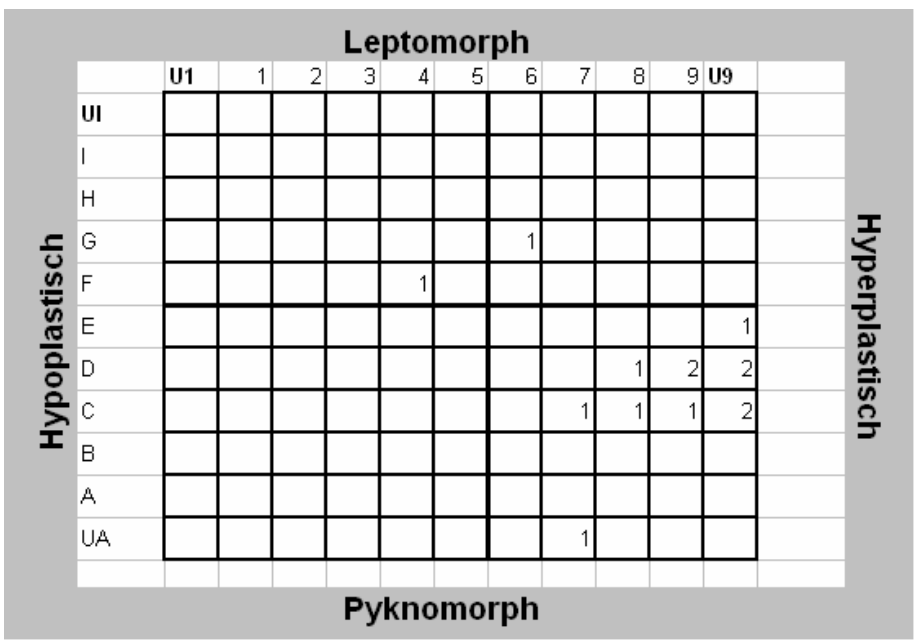

Figure 6. Conrad's chessboard sample: Experienced Muay Thai fighters

Table 2. AKS- Index according to Tittel and Wutscherk

\begin{tabular}{ll}
\hline AKS Index & \\
\hline students & 1.04 \\
\hline unexperienced & 1.05 \\
\hline experienced & \\
\hline Muay Thai fighters & 1.09 \\
\hline unexperienced & 1.16 \\
\hline experienced & \\
\hline
\end{tabular}




\section{DISCUSSION}

The results of the present study show that significant differences between the participants are given. While the majority of the students showed a great body height, the Muay Thai fighters were smaller. While the experienced students of physical education showed the highest value in body height with $184.1 \mathrm{~cm}$, the experienced Muay Thai fighters showed the lowest value in the height with the average of $177.2 \mathrm{~cm}$. It is interesting to note that comparing the body height of the participants of this study with the body height of fighters of the Superleague (2010), the fighters of the Superleague had the average body height of $190.2 \mathrm{~cm}$. This is significantly higher.

Although the experienced Muay Thai fighters were the smallest among the participants, their chest girth was the biggest with the average of $97.8 \mathrm{~cm}$ compared to the chest girth of the experienced students which had the average chest girth of $94.4 \mathrm{~cm}$.

The results achieved by the help of CONRAD'S method also show that the students' body composition tends to be between pycnomorphy and leptomorphy. Almost all the participants, however, demonstrated an hyperplastic tendency. The experienced Muay Thai fighters, however, show a greater tendency towards pycnomorphy.

Concerning the body weight, it is interesting to point out that the experienced students as well as the experienced Muay Thai fighters had the same average body weight. When regarding that the students in general were bigger than the Muay Thai fighters one could easily assume that the Muay Thai fighters have more body fat. This, however, was not the case. As the AKSIndex shows and the results by the Parnell's method: the Muay Thai fighers, especially the experienced ones had more muscle tissue while being significantly smaller. Comparing the AKS- Index with experienced Karate fighters shows that the experienced Muay Thai fighters had the same AKS- Index number of 1.16. The inexperienced Muay Thai fighters, as well as less experienced Karate fighters, show similar results of 1.09 versus 1.05 .

\section{CONCLUSION}

The results show clearly significant differences in the body composition between the experienced students of physical education and experienced Muay Thai fighters. For a martial art fighter the smaller size can be of advantage due to being able to move more quickly, being able to avoid punches and kicks. However being smaller, results in smaller extremities such as arms and legs, 
which makes it more difficult to reach the opponent. In this study the experienced Muay Thai fighters showed to have more muscle tissue than the students and were in general better trained. This fact can to a certain point be of advantage since punches and kicks can be made faster and harder.

\section{REFERENCES}

1. Bös K., Hänsel F., Schott N. (2004). Empirische Untersuchungen in der Sportwissenschaft. Hamburg, Czwalina.

2. Conrad K. (1963). Der Konstitutionstypus. Berlin, Göttingen, Heidelberg, Springer Verlag.

3. Fritsche J. (2006). Sportanthropometrische Untersuchungen zu Konstitutionstypologie von Kampfkünstlern der Sportart Karate. Frankfurt: Goethe Universität.

4. Martin R., Saller K. (1957). Lehrbuch der Anthropologie, 3. Auflage. Stuttgart: Gustav Fischer.

5. Moore K. (2008). Muay Thai. The Essential Guide to the Art of Thai Boxing. Johannesburg, Hirt und Carter.

6. Parizkova J., Buzkova P. (1971). Realtionship between skinfold thickness measured by Harpenden Caliper and densitometric analysis of total body fat in men. A methodical contribution to the international Biological Program. Human Biology, 43, 16-21.

7. Parnell R. W. (1958). Behaviour and physique. London, Arnold.

8. Raschka C. (2006). Sportanthropologie. Köln, Sportverlag Strauß.

9. Statistisches Bundesamt (2003). Mikrozensus 2003. Körperhöhe der Bevölkerung. Wiesbaden.

10. Statistisches Bundesamt (2009). Mikrozensus 2009. Körperhöhe der Bevölkerung. Wiesbaden.

11. Tittel K., Wutscherk H. (1972). Sportanthropometrie: Aufgaben, Bedeutung, Methodik und Ergebnisse biotypologischer Erhebungen. Barth.

\section{Address for correspondence:}

Priv.-Doz. Dr.med. Dr.rer.nat. Dr. Sportwiss. Cristoph Raschka

Institute of Sports Sciences

Julius-Maximilians-University Würzburg

Judenbühlweg 11. D-97082 Würzburg, Germany

E-mail: christoph.raschca@uni-wuerzburg.de 